\title{
Morphological and Molecular Alterations in 1,2 Dimethylhydrazine and Azoxymethane Induced Colon Carcinogenesis in Rats
}

\author{
Martina Perše and Anton Cerar \\ Institute of Pathology, Medical Experimental Centre, Medical Faculty, University of Ljubljana, Korytkova 2, 1105 Ljubljana, Slovenia \\ Correspondence should be addressed to Martina Perše, martina.perse@mf.uni-lj.si
}

Received 14 September 2010; Revised 30 October 2010; Accepted 29 November 2010

Academic Editor: Andrea Vecchione

Copyright (C) 2011 M. Perše and A. Cerar. This is an open access article distributed under the Creative Commons Attribution License, which permits unrestricted use, distribution, and reproduction in any medium, provided the original work is properly cited.

The dimethyhydrazine (DMH) or azoxymethane (AOM) model is a well-established, well-appreciated, and widely used model of experimental colon carcinogenesis. It has many morphological as well as molecular similarities to human sporadic colorectal cancer (CC), which are summarized and discussed in this paper. In addition, the paper combines present knowledge of morphological and molecular features in the multistep development of CC recognized in the DMH/AOM rat model. This understanding is necessary in order to accurately identify and interpret alterations that occur in the colonic mucosa when evaluating natural or pharmacological compounds in DMH/AOM rat colon carcinogenesis. The DMH/AOM model provides a wide range of options for investigating various initiating and environmental factors, the role of specific dietary and genetic factors, and therapeutic options in CC. The limitations of this model and suggested areas in which more research is required are also discussed.

\section{Introduction}

Colorectal cancer (CC) is one of the leading causes of cancerrelated morbidity and mortality in humans in western developed countries [1]. In recent years, increasing attention has been paid to environmental and food components, with the hope of identifying its preventive or carcinogenic effects $[2,3]$. Much effort has been dedicated to a search for natural or pharmacological preventive agents, which would block or attenuate CC process $[4,5]$.

There are several experimental models of CC, providing a wide range of options for investigating various initiating and environmental factors, the role of specific dietary and genetic factors, and therapeutic options in CC. These models, which can be broadly divided into induced and transgenic animal models, vary in their suitability for investigating each of these factors. Homologous recombination of random chemically induced mutagenesis has been used to generate a series of APC $(+/-)$ mice that exhibit mutation in codons 474, 716, 850, or 1638 of the APC tumour suppressor gene and encode a truncated gene product. Similar recombination approaches have also generated a mouse model with a mutation in the DNA mismatch repair genes. Mlh1 (+/-), Mlh1 (-/-), Msh6 (+/-), and Msh6 (-/-) mice exhibit accelerated small intestinal carcinogenesis. These animal models have been generated to study familial adenomatous polyposis (FAP) and hereditary nonpolyposis colorectal cancer (HNPCC) syndromes and are described elsewhere [6]. Among chemically induced animal models, 1,2 dimethylhydrazine $(\mathrm{DMH})$ and azoxymethane $(\mathrm{AOM})$ animal models are most frequently used [4, 7-9]. Induction of colon cancer by other chemical carcinogens, such as nitrosamines or heterocyclic amines is less frequently used [10-12], because $\mathrm{DMH}$ and $\mathrm{AOM}(\mathrm{DMH} / \mathrm{AOM})$ are less expensive, more potent and more convenient to use $[7,9]$. The DMH/AOM model of colon carcinogenesis is a valid, well-appreciated, and widely used model of experimental colon carcinogenesis. It shares many similarities to human sporadic CC, including similarities in the response to some promotional and preventive agents [4]. Today, it is a widely used model for the evaluation of environmental, dietary, and chemopreventive agents in the colon cancer process. It is also 
used to study morphologic and molecular mechanisms of the multistage development of colon cancer in order to elucidate new targets for chemoprevention $[12,13]$.

A number of excellent reviews on animal models of colon carcinogenesis $[6,12]$, including chemically induced carcinogenesis $[7,13,14]$, have recently been published. Various aspects of the applicability of the DMH/AOM animal model are demonstrated in these papers. However, in order accurately to identify and interpret alterations that occur in the colonic mucosa when assessing natural or pharmacological compounds in an animal model, understanding both the morphologic and molecular development of the CC process in this model is required. This paper, therefore, summarizes the present knowledge of morphological and molecular features in multistep development of CC in the $\mathrm{DMH} / \mathrm{AOM}$ rat model and its similarities to human sporadic CC. In addition, features and limitations of this model and suggested areas in which more research is required are also discussed.

\section{Induction of DMH/AOM Colon Carcinogenesis}

$\mathrm{DMH}$ and its metabolite $\mathrm{AOM}$ are widely used agents for the induction of colorectal carcinogenesis in rodents. DMH is metabolically activated in the liver by a series of reactions through intermediates $\mathrm{AOM}$ and methylazoxymethanol (MAM) to the ultimate carcinogenic metabolite, highly reactive methyldiazonium ion [15]. MAM can be excreted into the bile and transported to the colon (the development of small intestinal tumours distal to the entrance of the bile duct into the intestine is ascribed to this path) or enter directly into epithelial cells of the colon from blood circulation [15]. Some studies have also demonstrated that rat colon epithelial cells are capable of metabolizing DMH into the carcinogenic metabolite without previous metabolism by other tissues or colon bacteria $[16,17]$. The ultimate carcinogenic metabolite of DMH is responsible for methylation of the DNA bases of various organs, including epithelial cells in the proliferative compartment of the crypts, which result in a great loss of colonic cells by apoptosis, an increase in proliferation, and an apparent increase in mutations of colonic epithelial cells [18].

However, DMH/AOM are highly specific carcinogens that induce colorectal tumours in a dose-dependent manner [19]. Various rat and mouse strains differ in susceptibility to these carcinogens $[12,20]$. The susceptibility for $\mathrm{DMH} / \mathrm{AOM}$-induced colorectal carcinogenesis is also sex [21] and age dependent [22, 23]. Most commonly, 6 weeks old male F344, Wistar and Sprague-Dawely rats are used $[7,8]$. Colon carcinogenesis is usually induced by two s/c applications of DMH $(150 \mathrm{mg} / \mathrm{kg})$ or AOM $(15 \mathrm{mg} / \mathrm{kg})$ given one week apart. Using these protocols, animals are scored for intermediate biomarkers of colon carcinogenesis, termed aberrant crypt foci (ACF), 8-12 weeks after the application (short-term study) or for the number of colonic tumours 40 weeks later (long-term study). Chemopreventive treatment can begin before exposure to the carcinogen and during the initiation phase, during the promotion or progression phase, or through both phases. These protocols are used to assess the promotional or protective effects of the tested factor and when followed closely provide data that are quite reproducible (protocol explained in detail by Femia and Caderni [7] and Bird [9]).

Nevertheless, tumour outcome depends on the total amount of carcinogen administered and the latency period. In long-term studies, therefore, DMH is frequently administered weekly for 15 weeks in a relatively low concentration $(20 \mathrm{mg} / \mathrm{kg})$. Repeated injections of carcinogen are evident at a later stage of cancer development and not in the stage of preneoplastic lesions, that is, ACF [24] and result in higher tumour incidence and multiplicity than following one or two injections of a colon carcinogen $[19,24]$.

\section{Histopathological Nomenclature of Colorectal Epithelial Lesions}

$\mathrm{DMH} / \mathrm{AOM}$ colon carcinogenesis is a multistep process with morphological and histological features similar to those seen in human sporadic colon carcinogenesis $[25,26]$. It is widely accepted today that the adenoma to carcinoma sequence is characterized by recognizable histological changes that start with dysplastic aberrant crypts or intraepithelial neoplasia (IEN) $[27,28]$. These lesions then have the potential to progress to advanced adenomas, which have a significant potential to transform into adenocarcinomas [26].

3.1. Intraepithelial Lesions. The first lesions in the multistep development of CC cannot be seen grossly. They can be identified in histological sections of colon mucosa after careful histological examination as hyperplastic or dysplastic epithelial lesions [29] or on the surface of whole mount colon under low-magnification stereomicroscope as ACF [24, 25] or mucin depleted foci (MDF) $[28,30]$. It is important to bear in mind that visualization and identification of ACF or MDF on whole mount colon does not yield specific information on the histological features of these lesions. The structural and cytological features of ACF or MDF can be recognized or confirmed only after histological examination. Nevertheless, in order better to understand the histological background of ACF and MDA (which are described in the next section) as well as molecular alterations recognized and described at different stages of colon carcinogenesis, we will briefly summarize the histological criteria and classification of colorectal epithelial lesions in rodents, which share many similarities with human pathology $[26,29]$.

3.1.1. Hyperplastic Intraepithelial Lesions. Hyperplastic epithelial lesions are composed of a mixture of goblet and absorptive cells, with enlarged or sometimes crowded nuclei without stratification. Mitotic figures are limited to the lower two thirds of the crypts and are never observed on the surface of crypts. Nuclei are basally located, ovoid or round, with occasional visible nucleoli and usually uniformly dark. The luminal opening of crypts is slightly elevated from the surrounding normal mucosa and the crypts are 
elongated and occasionally branching, with partial mucin depletion [29]. It is worth mentioning that hyperplastic epithelium has never been observed in colonic tumours of the DMH/AOM rat model. It has only been found in intraepithelial lesions composed of a various number of crypts. The role of hyperplastic aberrant crypts in the process of colon carcinogenesis in $\mathrm{DMH} / \mathrm{AOM}$ models is not clear and is a matter of debate and further investigation.

3.1.2. Intraepithelial Neoplasia/Dysplasia. Inraepithelial neoplasia is a histological term for dysplastic lesions in the epithelial layer of colon mucosa that cannot be identified macroscopically but only after careful histological examination. The presence of dysplasia is regarded as early histopathological changes in the precursor lesions of colon cancer. The word dysplasia is used to describe structural and cytological alterations in the epithelium that predispose an organ to cancer development. IEN is synonymous with the terms atypical hyperplasia, microadenoma, carcinoma in situ, and dysplasia. Depending on the cytological and architectural features, IEN is classified as low grade or high grade. The differential criteria involve hypercelularity with enlarged, hyperchromatic nuclei, varying degrees of nuclear stratification, loss of polarity, high nuclear/cytoplasmic ratio, nuclear crowding, increased mitotic index, and decreased mucine excretion [29].

3.2. Tumours. Pathological changes that can be seen macroscopically on the surface of colon mucosa as pedunculated or broad-based, slightly elevated, flat, or depressed (sessile or nonpolypoid) masses/lesions are called tumours. The incidence of colon tumours is the most reliable endpoint for evaluation of the chemopreventive effects of substances. Further histological examination is required to determine the malignant or benign character of tumours.

3.2.1. Adenomas. Tumours confined to the mucosa are benign neoplasms that are called adenomas. On the basis of the histologic type, adenomas can be tubular (when more than $75 \%$ of the adenoma is composed of branching tubules), villous (more than $75 \%$ of adenoma is composed of villous structures), or tubulovillous ( $25 \%-75 \%$ of adenoma composed of both tubular and villous structures). Depending on the degree of dysplasia on the most severely dysplastic area of each tumour, adenomas are graded as low or high [29].

3.2.2. Adenocarcinomas. Tumours that penetrate through the muscularis mucosa are malignant lesions, histologically denoted adenocarcinomas (well, moderately, or poorly differentiated). Based on the histological type, they are further classified into tubular, tubulovillous, or villous adenocarcinomas (as with adenomas), mucinous adenocarcinomas (if more than $50 \%$ of the lesion is composed of extracellular mucin and signet-ring cell can be present), signet-ring cell adenocarcinomas (if more than $50 \%$ of tumour cells with prominent intracytoplasmic mucin are present), and undifferentiated carcinoma (if no glandular structure is present) [29].

\section{Biomarkers of Colon Carcinogenesis}

In the past, assessment of chemopreventive substances was based on the incidence of tumours. Since the development of tumours is a relatively lengthy process, taking around 6-8 months to develop in the DMH/AOM rat model, preneoplastic lesions can be used as biomarkers for assessing the risk of developing colon cancer or for identifying modulators of colon carcinogenesis in short-term studies [9]. The use of preneoplastic lesions as biomarkers was not possible until 1987, when Bird [31] developed a simple, rapid and cheap methodological approach to detecting ACF $[25,31]$. In the last decade, additional biomarkers of colon carcinogenesis have been identified, such as dark ACF [32], flat ACF [33], dysplastic ACF [34], MDF [30], and $\beta$-catenin accumulated crypts (BCAC) [35]. Their characteristics and application in short-term studies are briefly described.

4.1. ACF. ACF are the first lesions in the development of CC that can be identified microscopically on the surface of the whole mount colon mucosa after methylene blue staining. They have been identified in carcinogen treated rodents $[25,31]$ and in humans at high risk of developing CC (personal or familial history) [36, 37]. A number of studies in rodents and humans, including molecular analysis, have shown that ACF are lesions that are a valuable intermediate biomarker in the development of colon carcinogenesis [38]. ACF have to date been used as an endpoint in identifying and assessing the preventive or promotional role of natural and pharmacological compounds, as well as dietary and environmental factors, in the process of colon carcinogenesis $[4,5]$.

An increasing number of studies have demonstrated that ACF in both animals and humans are a heterogeneous group of lesions containing multiple genetic, epigenetic, and phenotypic alterations [37-40]. Histologically, ACF exhibit variable features, ranging from mild atypia to severe dysplasia. Most ACF show a hyperplastic character, while only a small subgroup of ACF has been found to contain intraepithelial neoplasia (such as severe dysplasia, microadenoma, or carcinoma in situ). It has been shown that ACF with hyperplasia possess different genetic and epigenetic alterations than ACF with dysplasia, and some studies have suggested that ACF possessing hyperplastic feature may not be directly related to tumorigenesis $[27,28]$. However, there are reports suggesting that some ACF possessing hyperplasic features may progress to ACF with dysplasia $[40,41]$.

Nevertheless, ACF are useful biomarkers for the screening of compounds for their chemopreventive activities [5, 42]. When using ACF as biomarkers, it is important to take into consideration that ACF are a heterogeneous group of lesions. The total number of ACF may be considered to be a valid biomarker only at a very early stage of carcinogenesis, while, in subsequent weeks, ACF with higher crypt multiplicities (more than 4 crypts) are considered 
a more specific biomarker than the total number of ACF. In more advanced stages of colon carcinogenesis, ACF may not be a reliable intermediate biomarker of colon carcinogenesis (explained in detail by Bird and Good [24] and Raju [42]). It is also important to mention that ACF are not equally distributed among the proximal, middle, or distal colon. The majority of ACF develop in the middle and distal colon [4345], which needs to be taken into account when using ACF as biomarkers (comprehensively discussed by Bird $[24,25]$ and Raju [42].

4.2. Subgroup of ACF with Dysplastic Features (Dark, Flat, and Dysplastic ACF). Since dysplasia is widely accepted as an indication of an increased risk of progression to cancer, it has been suggested that dysplastic crypts may be more directly associated with tumorigenesis than ACF [27]. Dysplastic ACF have recently been identified by various investigators using different approaches. Ochiai et al. [34] developed a differential staining method to identify dysplastic ACF, while identification of flat ACF [33] and dark ACF [32] were based on the surface morphology of ACF. However, all these lesions have been observed as subgroups of ACF with thicker epithelial lining, compressed luminal openings and mildly enlarged crypts, which were not elevated from surrounding epithelium. Histologically, all these subgroups of ACF have possessed dysplastic features with absent or scarce mucin production and have shown cytoplasmic and nuclear accumulation of $\beta$-catenin [32-34]. Based on a description of surface morphology (except the description of staining intensity) and histological characteristics, it is likely that flat, dark, and dysplastic ACF may represent the same group of ACF with dysplastic features. If each of these lesions represents a different subgroup of dysplastic ACF, their use as biomarkers would probably be questionable or confusing. Further investigations and determination of their relations are certainly needed before they can be used as biomarkers.

4.3. $M D F$. MDF are identified on the mucosal surface of unsectioned colon after staining with high-iron diamine alcian blue (HID-AB), which visualizes crypts with mucous production [30]. Identification of MDF is based on a scarce or absent production of mucous, which is a common feature of severe dysplasia. In contrast to ACF, which are histologically heterogenous, MDF are composed of dysplasic crypts, which display frequent genetic and epigenetic alterations observed also in colon cancer [46-49]. It has been shown that MDF appear 7 weeks after carcinogen administration and their number and multiplicity increases with time. MDF have been demonstrated as a potential biomarker for evaluation of the chemopreventive effects of natural or pharmacological compounds in colon carcinogenesis [50]. Since few studies have evaluated MDF as a biomarker, further investigations are needed to evaluate their role in colon carcinogenesis.

4.4. BCAC. In contrast to ACF and MDF, which can be identified on the surface of the whole mount colon, identification
TABLE 1: Nomenclature of colorectal lesions according to their morphological appearance on whole mount colon (low magnification) or according to their histological characteristics identified in embedded and stained colon sections under a high-magnification microscope.

\begin{tabular}{ll}
\hline $\begin{array}{l}\text { Morphological } \\
\text { description }\end{array}$ & Histological description \\
\hline $\begin{array}{l}\text { Tumour } \\
\text { (i) polypoid }\end{array}$ & Adenomas: \\
& (i) low-grade dysplasia \\
(ii) high-grade dysplasia \\
Adenocarcinomas: \\
(ii) nonpolypoid
\end{tabular}$\quad \begin{aligned} & \text { (i) well, moderate, and poorly } \\
& \text { (ii) mucinous adenocarcinomas } \\
& \text { (iii) signet-ring cell adenocarcinomas } \\
& \text { (iv) solid or undifferentiated carcinomas }\end{aligned}$

ACF (methylene

blue)

(i) "dysplastic"

Intraepithelial lesions:

(ii) dark

(i) hyperplastic

(ii) dysplastic/intraepithelial in situ neoplasia/microadenoma/carcinoma

(iii) flat

MDF (HID-AB)

(a) BCAC (immunohistochemical staining)

ACF, aberrant crypt foci; BCAC, $\beta$-catenin accumulated crypts; MDF, mucin depleted foci; HID-AB, high-iron diamine alcian blue.

of BCAC is based on an immunohistochemical method in sectioned colon [35]. BCAC are intraepithelial lesions that accumulate $\beta$-catenin protein in the cytoplasm and nucleus and harbor frequent $\beta$-catenin (Ctnnb1) mutations. Histologically, BCAC shows dysplasia with reduced or absent mucin production $[35,51]$.

Based on the assumption that mutations in the $\beta$-catenin gene or accumulation of $\beta$-catenin are the necessary first step in rat colon carcinogenesis, crypts with increased $\beta$ catenin expression have been proposed as a more relevant biomarker of colon cancer than ACF [27, 28, 35, 51]. However, histological identification and quantification of BCAC is relatively costly, tedious, and time consuming, which limits the use of BCAC as a biomarker.

However, we do not know at present whether BCAC, MDF, dark, flat, and dysplastic ACF are related lesions. The development of these dysplastic lesions is clearly related to the early development of tumours. Histologically, all these lesions show dysplasia with scarce or absent production of mucin and accumulate $\beta$-catenin in the cytoplasm and/or nucleus. Accordingly, it is possible that all these lesions are only dysplastic subgroups of ACF, which may predict tumour outcome better than ACF itself. However, first investigations suggest that this assumption may not be correct, because these lesions may not overlap completely [52, 53]. Further investigations are, therefore, needed to elucidate their features, evaluate relations and discrepancy among them and to identify the reason for discrepancy. 

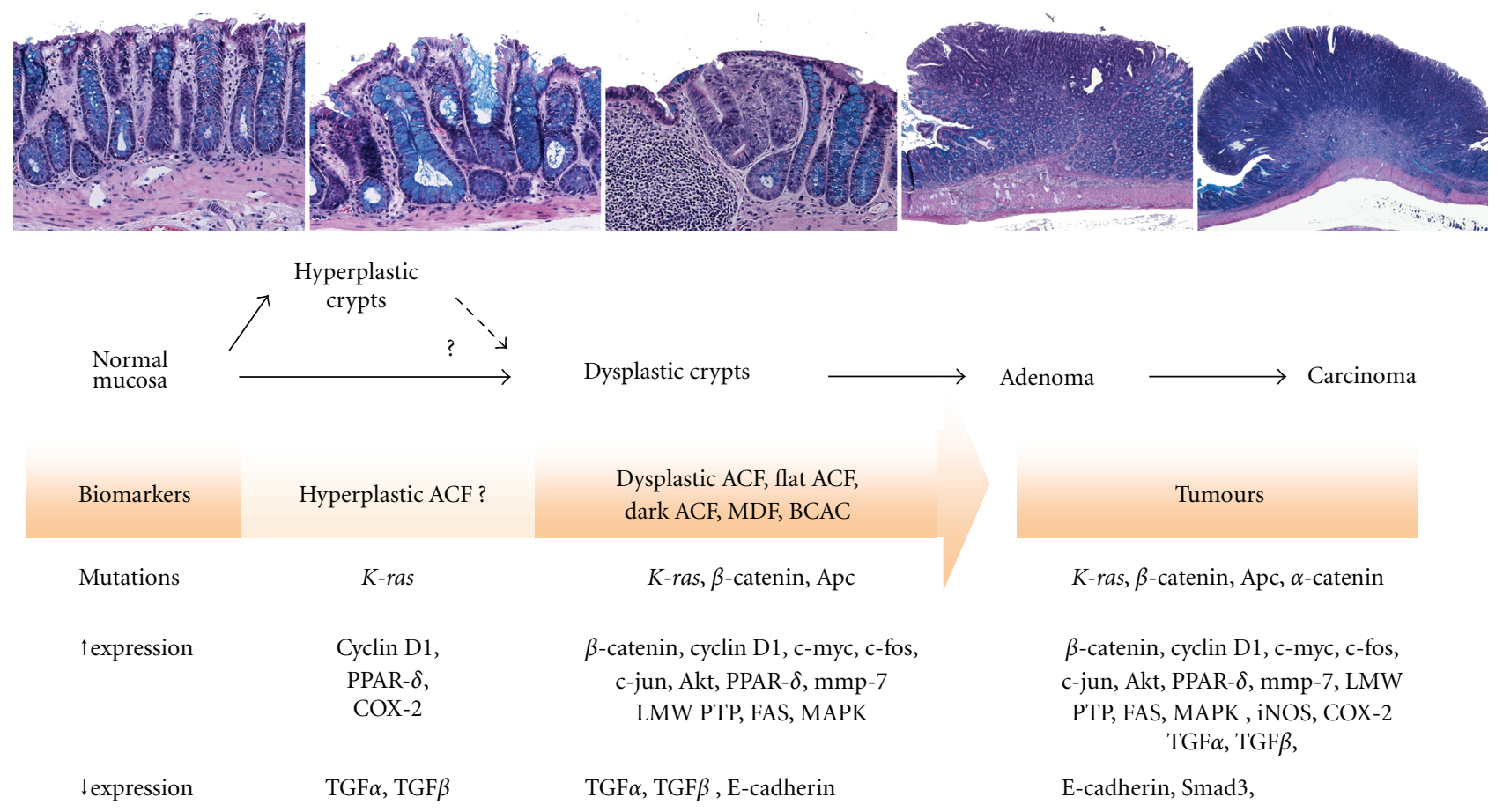

FIGURE 1: Phenotypic, genetic, and epigenetic alterations involved in multistep development of colon carcinogenesis in the DMH/AOM rat model.

\section{Gene Mutations in DMH/AOM Colon Carcinogenesis}

Colon carcinogenesis is a multistage process, involving multiple genetic and epigenetic changes that provide tumour cells with a selective advantage to expand their clones [54]. The stepwise development of CRC from dysplastic crypts, adenomas to carcinomas provides opportunities for the investigation and identification of molecular alterations at various stages of tumour development [24, 25, 55]. Genes that are mutated at different stages of colorectal carcinogenesis in human sporadic CC have been found to be also mutated in DMH/AOM-induced colon carcinogenesis and are described and discussed below.

5.1. Apc/ $\beta$-Catenin. Mutations in the tumour suppressor gene, $A P C$, are responsible for an inherited predisposition to colon cancer, FAP. APC mutations are also believed to be the earliest events in the formation of sporadic colon adenomas [54]. They have been identified in up to $80 \%$ of sporadic colon tumours in humans [56]. The most common APC mutation in human colon adenomas is $A P C$ loss of heterozygosity $(\mathrm{LOH})$, which causes truncation of the protein and its inactivation. It is believed that the main function of APC is the regulation of free $\beta$-catenin in concert with glycogen synthase kinase $3 \beta$ (GSK-3 $\beta$ ) and other proteins $[54,57]$. It has been found that half of human colon tumours with intact APC protein have a mutation in the $\beta$-catenin gene [26].

Apc mutations have also been identified in colorectal epithelial lesions in the DMH/AOM rat model, albeit to a lesser degree and in a different region from that observed in humans [58]. In DMH/AOM-treated rats, up to $33 \%$ of colon tumours harbour Apc mutations. These Apc mutations have frequently been found located upstream from the region corresponding to the human APC mutation cluster region (nt 3,186-3,810; nt 3078 and 3835 in exon 15). They have mostly been missense or truncated point mutations ( $G$ to $\mathrm{A}$ and $\mathrm{C}$ to $\mathrm{T}$ transition) [58-60]. A deletion of the region containing the $A p c$ gene has recently been found in one out of ten tumours, suggesting that LOH may also be involved in inactivation of $A p c$ in this model [61].

In the $\mathrm{DMH} / \mathrm{AOM}$ rat model, $\beta$-catenin mutations are a more frequent event than $A p c$ mutations, occurring in up to $77 \%$ of tumours (Table 2 ). They are mainly point mutations ( $G$ to A transitions) localized in the GSK-3 $\beta$ phosphorylation consensus motif, which result in the inhibition of GSK3 $\beta$-dependent phosphorylation of $\beta$-catenin. However, $A p c$ mutations or mutations in $\beta$-catenin have only been observed in the $\mathrm{DMH} / \mathrm{AOM}$ rat model and in human CC in neoplastic/dysplastic lesions, that is, microscopic dysplastic epithelial lesions, adenomas, and adenocarcinomas (shown in Table 2) but not in hyperplastic lesions $[35,48,58,59,62$, 63].

5.2. K-Ras. The K-RAS gene encodes membrane bound protein with intrinsic GTPase activity, which is involved in the regulation of a number of important normal cellular functions, including proliferation, differentiation, and apoptosis. Single point mutations at specific sites within ras genes activate their oncogenic potential [64]. K-RAS mutations have been observed with various frequencies $(\sim 40 \%-50 \%)$ 
in human colorectal neoplastic lesions, as well as ACF with hyperplastic epithelium. It has been reported that $K$-RAS is mutated in fewer than $10 \%$ of small adenomas (less than $1 \mathrm{~cm}$ in size), in about 50\% of large adenomas (larger than $1 \mathrm{~cm}$ ) and in approximately $50 \%$ of carcinomas [56].

In $\mathrm{DMH} / \mathrm{AOM}$ rat colon carcinogenesis, mutations in the $K$-ras gene are point mutations ( $\mathrm{G}$ to A transitions), observed mostly in codon 12 , rarely in codon 13 or 59 . The frequency of $\mathrm{K}$-ras mutations in rat colon carcinogenesis has been found to be variable, particularly in studies without a description of the histological features or size of the analyzed tumours [65-68]. Nevertheless, some studies have demonstrated that $K$-ras mutations are less frequent in small adenomas (on average $\sim 16 \%$ ), while more frequent in large adenocarcinomas $(\sim 53 \%)[62,69]$. On the basis of those studies, it appears that $K$-ras mutations in the DMH/AOM rat model are as frequent as in human colon carcinogenesis. As in humans, a $\mathrm{K}$-ras mutation has been observed more frequently in ACF with hyperplastic epithelium than in ACF with dysplastic features $[40,62,70,71]$. The mutation of $\mathrm{K}$-ras may thus be involved in the formation of the ACF lesion and promotion of lesion growth but is probably not essential. The fact that $K-R A S$ mutation is frequently and APC mutation very rarely observed in ACF in humans has triggered debate about the role of $K-R A S$ mutation in colon carcinogenesis (discussed by Pretlow [37]).

5.3. p53. Although aberration of the tumour suppressor P53 is a very common genetic lesion identified in human carcinomas, no mutations in the $p 53$ gene in DMH/AOM rat colon carcinogenesis have been found by the single-strand conformation polymorphism method, direct sequencing or immunohistochemical analysis [59, 66, 72, 73]. Mutations in the $p 53$ gene have been investigated in regions (exon 57) corresponding to the most commonly mutated regions in human colon cancer (exon 5-8) [59]. It is interesting that positive reactivity for p53 in ACF $(27 / 65 ; 42 \%)$ and adenocarcinomas $(6 / 8 ; 25 \%)$ by immunohistochemically was one of the first reported alterations in ACF [74].

5.4. Genomic Instability. Two types of genomic instability have been found in human colon cancer, that is, microsatellite instability (MSI) and chromosomal instability (CIN). MSI leads to an increase in the rate of subtle DNA changes whereas CIN enhances the rate at which gross chromosomal changes occur during cell division, such as chromosome breaks, duplication, rearrangements, and deletions such as $\mathrm{LOH}$ on varies sites in the genome [75].

In the DMH/AOM model, one or two chromosomal aberrations (amplification or deletion from 66 to $2135 \mathrm{~kb}$ in length) were found in 4/10 of tumours using a-CGH analysis. In one case, even a $\mathrm{LOH}$ of the $A p c$ gene on chromosome 18 was found [61]. On the other hand, an investigation based on RAPD analysis with 21 random primers (GC rich) detected small alterations in the genome in $100 \%$ of analyzed tumours (16/16) and even in $70 \%$ of ACF (7/10) [67]. When tumours were analyzed on MSI using 10 different microsatellite DNA markers, it was found that $29 \%$ of colonic tumours (13/45) showed MSI in at least one locus and 15\% of tumours (7/45) showed MSI at multiple loci (MSI-high tumours) [76]. Using a PCR-based approach with 6 DNA markers, MSI was reported in 21\% of tumours (4/20 adenomas and 2/8 carcinomas), mostly as single-microsatellite change (insertion or deletion), and only one tumour showed instability at three loci [67].

These results suggest that genomic instability is an important molecular event in DMH induced colon carcinogenesis. It seems that, unlike in human colon cancer, chromosomal alterations in this model are relatively infrequent. Much more frequent events in the DMH/AOM model are small alterations in the genome that are involved in the very early stages of colon carcinogenesis. Single nucleotide changes, which have been found to be responsible for $A p c$, $\beta$-catenin and $K$-ras mutations, are apparently widespread and very frequent alterations in the genome of this model. This carcinogen generates the methylated DNA adducts O6methylguanine, which, if not repaired, may mispair with thymidine during DNA replication, resulting in a G:C to A:T transition.

\section{Altered Expression in DMH/AOM Colon Carcinogenesis}

Not only mutations but also many of the cellular and molecular defects found in human colon carcinogenesis have also been observed in DMH/AOM rat colon carcinogenesis. These alterations have been found to be involved in various pathways, such as the Wnt pathway, K-ras pathway, tumour growth factor $\beta$ (TGF $\beta$ ) signaling pathway, and inflammatory related process, which play important role in colon cancer.

6.1. Wnt Pathway. The Wnt pathway has been implicated as a crucial step in the initiation and development of colonic tumorigenesis. In the absence of the extracellular Wnt signal, free $\beta$-catenin is bound to the APC-axin-conductin-GSK3 $\beta$ complex. Phosphorylation of $\beta$-catenin by this complex marks it for ubiquitination and subsequent proteolytic degradation by the proteasome. When APC or $\beta$-catenin is mutated, $\beta$-catenin cannot be degraded but accumulates in the cytoplasm and translocates into the nucleus, where it binds to T-cell factor (TCF) and activates the Wnt target genes [80-82].

In normal colon epithelial cells, $\beta$-catenin is highly expressed in the cell membrane and not detected in the cytoplasm or nucleus of cells [63]. In all dysplastic colorectal epithelial lesions (dysplastic ACF, dark ACF, flat ACF, BCAC, MDF, adenomas, and adenocarcinomas), but not in hyperplastic lesions, $\beta$-catenin expression is found to be increased in the cytosol and nucleus [14, 77, 83]. Aberrant expression of $\beta$-catenin has been associated with mutations in Apc or $\beta$-catenin, but has also been present in lesions without either Apc or $\beta$-catenin mutations [68], suggesting that aberrant expression of $\beta$-catenin may be the result of altered expression of one of the many proteins with which $\beta$-catenin interacts, such as axin, conductin, or Ecadherin [82]. In fact, inactivation of E-cadherin, which 
TABLE 2: Frequencies of gene mutations found in biomarkers and different stages of colon carcinogenesis in the DMH/AOM rat model.

\begin{tabular}{|c|c|c|c|c|c|c|c|}
\hline Gene & $\mathrm{ACF} / \mathrm{MDF}(n)$ & Histologic diagnosis $(n)$ & Tumours $(n)$ & Adenomas $(n)$ & Carcinomas $(n)$ & Carcinogen & Ref. \\
\hline \multirow[t]{6}{*}{ Apc } & $0 \%$ ACF (66) & - & $14.3 \%(27)$ & (17) & $(10)$ & $\mathrm{AOM}$ & [58] \\
\hline & - & $22.2 \%$ dysplasia (18) & - & - & - & DMH & [59] \\
\hline & & $15.4 \%$ AC (13) & & & & & \\
\hline & - & - & $8.8 \%(57)$ & - & - & DMH & [60] \\
\hline & $0 \%$ ACF (24) & - & $30.4 \%(23)$ & $33.3 \%(12)$ & $27.3 \%(11)$ & DMH & [48] \\
\hline & $25 \% \operatorname{MDF}(24)$ & & & & & & \\
\hline \multirow[t]{8}{*}{$\beta$-catenin } & - & - & - & - & $75 \%(8)$ & $\mathrm{AOM}$ & [63] \\
\hline & $15.4 \% \mathrm{ACF}(13)$ & $0 \%$ hyperplasia $(10)$ & $68.8 \%(32)$ & $33 \%(6)$ & $77 \%(26)$ & $\mathrm{AOM}$ & [62] \\
\hline & & 66\% dysplasia (3) & & & & & \\
\hline & $20 \%$ ACF (15) & 67\% BCAC (15) & - & - & - & $\mathrm{AOM}$ & [35] \\
\hline & - & - & $32.4 \%(68)$ & - & - & $\mathrm{AOM}$ & [68] \\
\hline & - & - & $37 \%(119)$ & - & - & DMH & [60] \\
\hline & $7 \%$ ACF (27) & - & $40 \%(15)$ & - & - & DMH & [46] \\
\hline & $25 \% \operatorname{MDF}(28)$ & & & & & & \\
\hline \multirow[t]{12}{*}{ K-ras } & - & - & - & - & $66 \%(44)$ & DMH & [69] \\
\hline & $32 \%$ ACF (19) & - & - & - & $\mathrm{AC} ?$ & $\mathrm{AOM}$ & [70] \\
\hline & 7.4\% ACF (27) & - & $22 \%(50)$ & $4.3 \%(23)$ & $37 \%(27)$ & $\mathrm{AOM}$ & [65] \\
\hline & - & - & - & - & $60 \%$ & DMHAOM & [66] \\
\hline & $53.8 \%$ ACF (13) & $70 \%$ hyperplasia $(10)$ & $25 \%(28)$ & $0 \%(2)$ small & $8 \%$ (12) small & $\mathrm{AOM}$ & [77] \\
\hline & & 0\% dysplasia (3) & & & $43 \%$ (14) large & & \\
\hline & - & - & $16.7 \%(30)$ & $9 \%(22)$ & $37.5 \%(8)$ & $\mathrm{AOM}$ & [67] \\
\hline & - & - & $58 \%(43)$ & $60 \%(10)$ & $58 \%(33)$ & DMH & [78] \\
\hline & - & - & $16.7 \%(84)$ & - & - & $\mathrm{AOM}$ & [68] \\
\hline & $27 \%$ ACF $(6 / 22)$ & - & - & - & - & $\mathrm{AOM}$ & [79] \\
\hline & $100 \%$ ACF (14) & - & $5.5 \%(18)$ & $11 \%$ (9) small & $0 \%(9)$ small & DMH & [47] \\
\hline & $23 \% \operatorname{MDF}(13)$ & & & & & & \\
\hline \multirow[t]{3}{*}{ P53 } & - & - & - & - & $0 \%(20)$ & $\mathrm{AOM}$ & [73] \\
\hline & - & - & - & - & $0 \%(10)$ & MAM & {$[72]$} \\
\hline & - & $0 \%(31)$ & - & - & - & DMH & [59] \\
\hline
\end{tabular}

Number in parenthesis denotes the total number of colon lesions analyzed. MSI, microsatellite instability; ACF, aberrant crypt foci; MDF, mucin depleted foci; $\mathrm{BCAC}, \beta$-catenin accumulated crypts; $\mathrm{AC}$, adenocarcinoma in situ; —: not reported.

is normally bound with $\beta$-catenin and $\alpha$-catenin into the intercellular adhesion complex of epithelial cells and is a negative regulator of colonic epithelial cell proliferation, has already been described in human colon cancer and in ACF of AOM treated rats [84]. Loss of the region containing the $\alpha$-catenin gene has also been found in adenocarcinomas of this model [61]. Recent investigations of the Wnt pathway have shown that activation and/or downstream stimulation of the transcriptional activity of $\beta$ catenin can be affected by various signaling pathways and factors, such as the mTOR signaling pathway and FOXO proteins [81]. Aberrant expression of $\beta$-catenin, which is frequently observed in the DMH/AOM model, therefore offers an opportunity to elucidate mechanisms involved in $\beta$-catenin overexpression and to identify its downstream targets in colon carcinogenesis. Well-known downstream targets of APC/ $\beta$-catenin/Tcf- 4 mediated transcriptional activation in colorectal neoplasia include genes such as cyclin D1, c-myc, which have important roles in proliferation, apoptosis, and cell-cycle progression and are responsible for tumour formation [82]. Cyclin D1 and c-myc have been found to be overexpressed in several stages of $\mathrm{DMH} / \mathrm{AOM}$ induced rat colon carcinogenesis $[84,85]$. In one study, an inverse correlation between increased Apc expression level and decreased c-myc mRNA expression was reported [86]. Overexpression of $\beta$-catenin has been found to be correlated with increased expression of $\mathrm{mmp}-7$, the protein responsible for loss of cell adhesion and separation leading to further unlimited cell growth [32]. A mutation in $\beta$ catenin has been found to have no correlation with COX2 expression [68]. PPAR- $\delta$, a target of the Wnt or K-ras pathway that may function as an integrator of transcription repression and nuclear receptor signaling [87] and has been found to be elevated in DMH/AOM-induced adenomas and adenocarcinomas (10/10) [88].

6.2. K-Ras Pathway. Mutations in the K-ras gene are responsible for activation of the K-ras pathway, which is implicated in colon carcinogenesis in humans and rats $[14,64]$. In human tumours, as well as in tumours of AOM-treated rats, 
increased expression of Akt, a downstream target of the Kras pathway, has been found [89]. Akt plays an important role in the PI3K/Akt pathway, which is implicated in a variety of cellular processes, such as glucose metabolism, cell proliferation, apoptosis, transcription, and cell migration. PI3K/Akt promotes cyclin D1, which has been found to be overexpressed in tumours with a K-ras mutation [68]. In addition, activation of the MEK/MAPK/ERK pathway, another downstream K-ras signaling, has been found in tumours without K-ras mutation. Activation of this pathway has been associated with overexpression of c-erbB-2 receptors and decreased expression of GTPase activating protein (GAP), resulting in constitutive activation of normal K-ras protein. However, it has been found that in tumours with constitutively activated nonmutated K-ras, protein cyclin D1 expression was not increased. K-ras gene mutation and/or protein activation increased COX-2 expression in tumours [68].

The importance of the K-ras pathway in colon carcinogenesis and possible therapeutic targets in this pathway are described elsewhere $[13,64]$. EGFR or P-tyr showed no altered expression or distribution between ACF and normal colonic mucosa by immunostaining [90].

6.3. TGF $\beta$ Pathway. Transforming growth factor alpha and beta (TGF $\alpha$ and TGF $\beta$ ) have been implicated in DMH/AOMinduced colon carcinogenesis. TGF $\beta$ and TGF $\alpha$ expression has been found to be reduced in ACF with hyperplasia or dysplasia $[24,90]$ but TGF $\beta 1$ enhanced in colonic tumours [24], adenomas or adenocarcinomas (10/10) when examined by immunohistochemistry and Northern analysis [91]. TGF $\beta$ has been found to have a dual role. In normal cells, it stops the cell cycle at the G1 stage, to stop proliferation, induce differentiation or promote apoptosis and thus exerts tumour suppressive effects. In cancer cells, it also modulates processes such as cell invasion, immune regulation, and microenvironment modification that cancer cells may exploit to their advantage [92]. In adenocarcinomas of the DMH/AOM rat model, increased expression of TGF $\beta 1$ (Tgfb1), their receptors (Tgfrb1 and Tgfrb2), and receptor-activated Smads (Smad2 and Smad4) has been found, while expression of Smad 3 was downregulated [61]. It has been found that TGF $\beta$ and COX-2 were concurrently overexpressed in the same colonic neoplastic lesions in AOM-treated rats, suggesting that COX-2 expression in AOM-induced colonic tumour could, in part, be due to the overexpression of TGF $\beta$ [91].

6.4. Other. Inflammation-related processes have also been shown to be involved in the development of both human and $\mathrm{DMH} / \mathrm{AOM}$-induced colon carcinogenesis [14, 93]. Increased expression of iNOS and COX-2 in epithelial cells have frequently been observed in DMH/AOM-induced colon adenocarcinomas, adenomas, and ACF with dysplasia but no detectable changes in the epithelial expression of these proteins in ACF with hyperplasia has been found $[62,84,94]$. COX-2, as well as iNOS enzymes, have been recognized as a promising target for colon cancer prevention. Consequently, many novel COX-2 inhibitors and NO inhibitors have been considered to be chemopreventive agents on DMH/AOMinduced colon carcinogenesis $[95,96]$. The role of iNOS and COX-2 in DMH/AOM-induced colon carcinogenesis and its involvement in different pathways of carcinogenesis is excellently described by Takahashi and Wakabayashi [14].

In colon adenocarcinomas of the DMH/AOM rat model, many other pathways such as those related to cell cycle, RNA and protein metabolism, as well as pathways related to extracellular matrix remodeling, inflammatory processes and fatty acid oxidation, have been found to be upregulated [61]. Fatty acid synthase (FAS) has been found to be overexpressed in a variety of human cancers, including in ACF of human CC [97] and in AOM-treated rats in large ACF with dysplastic epithelium [98]. It appears that FAS plays an important role in the growth and survival of cancer cells, because it is implicated in increased endogenous lipogenesis of cancer cells. FAS inhibitors have been shown to decrease cell proliferation and induce apoptosis in cancer cell lines and have been suggested as a potential target of chemoprevention in colon cancer [98].

Increased expression of the low molecular weight protein tyrosine phosphatase (LMW-PTP), one of phosphotyrosine protein phosphatases involved in modulation of cell phosphorylation, which plays a role in the production of signals necessary for various cellular events, such as growth, migration, and invasion of normal and malignant cells, has been found in adenocarcinomas of DMH-treated rats and human colon tumours [99].

A comprehensive study on gene expression profile and genomic alteration in $\mathrm{DMH}$-induced colonic tumours in rats was recently performed, which confirmed the aforementioned molecular alterations in colon carcinogenesis and revealed other pathways implicated in tumour development that are also documented in human colon tumours [61]. This further demonstrates that the DMH/AOM rat model is a valuable tool for studying the molecular mechanisms involved in colon carcinogenesis and offers an excellent opportunity for evaluation of the effect of chemopreventive agents on CC development. Since DMH/AOM administration has been shown to affect oxidative status in the circulation [100] and different tissues of rats, such as heart [101], liver [102], and small and large bowel [103], this model has also been used for an evaluation of antioxidant activities of natural or pharmacological compounds and their involvement in colon carcinogenesis [104-106]. This model thus offers an opportunity to study and assess many therapeutic targets involved in the CC process.

\section{Distal and Proximal Colon Carcinogenesis}

It has been found that proximal colonic neoplasms in humans have distinct characteristics in terms of histology and molecular genetics. They are generally less differentiated and have a higher propensity for microsatellite instability than distal ones [88]. According to our experience, the majority of colon tumours in the DMH/AOM rat model are located in the distal colon, while are less frequent in the proximal colon. Histologically, tumours in the distal 


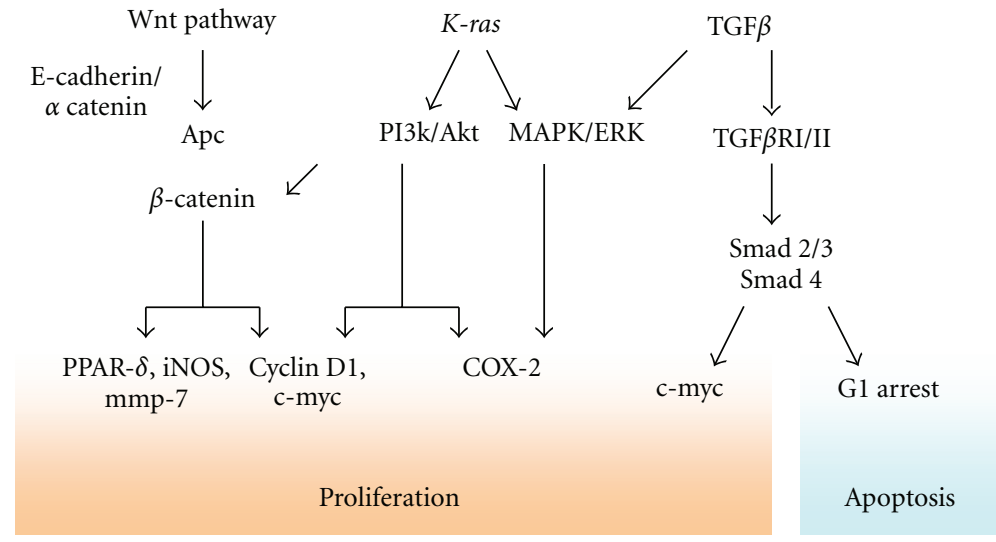

FIGURE 2: Signaling pathways involved in the development of colon carcinogenesis in the DMH/AOM rat model.

colon are mostly adenomas and well or moderately differentiated adenocarcinomas; in the proximal colon, tumours are mostly poorly differentiated, mucinous, or signet-ring cell adenocarcinomas. Similar observations have been reported by other investigators [43, 107]. In addition, ACF density is significantly and progressively higher from the proximal colon towards the distal, being the highest in the middle and distal colon, which is in accordance with the location of adenomas and carcinomas [43-45]. Observed differences in the histological characteristics of colorectal epithelial lesions between the distal and the proximal colon in rats support the assumption of two distinct pathways in colon carcinogenesis in the DMH/AOM rat model. It is believed that in the middle and distal colon, histogenesis follows ACFadenoma-carcinoma sequences, while in the proximal colon, poorly differentiated mucin-secreting carcinomas arise de novo without an intermediate stage of colon carcinogenesis $[8,43,107]$. Some studies have indicated that proximal and distal tumours in the DMH/AOM rat model also have distinct characteristics in terms of kinetic features [108], sensitivity to carcinogens [24], chemotherapy [88], and Kras expression $[69,99]$. In normal colon, mucosa differences in apoptosis and expression of COX-2, PPAR- $\delta$ (higher in distal than proximal colon) have also been reported [88]. All these observations are in line with reports on human CC and suggest that proximal and distal colon tumours are different entities. However, whether proximal and distal colon tumours in the DMH/AOM rat model have distinct molecular features has not yet been investigated.

\section{Limitations of the DMH/AOM Rat Model}

$\mathrm{DMH} / \mathrm{AOM}$-induced models are often criticized due to their exposure to DMH or AOM, which is believed not to be a common event in humans. However, humans are often exposed to hydrazine derivatives, because they are natural components of mushrooms and tobacco, constituents of herbicides, rocket fuel, and drugs [109]. The only difference is that animal models are exposed to DMH/AOM in much higher concentrations than humans. However, if we look at the definition of an animal model, it can be seen that the mode of induction is not a matter of debate or judgment of a good animal model. By definition, an animal model is "a living organism in which normative biology or behavior can be studied, or in which a spontaneous or induced pathological process can be investigated, and in which the phenomenon in one or more respects resembles the same phenomenon in humans or other species of animal" [110]. In the present paper, we have shown many similarities and common features between human and DMH/AOMinduced colon carcinogenesis, which demonstrate that the $\mathrm{DMH} / \mathrm{AOM}$ rat model is a valuable and suitable model for assessment of dietary and chemopreventive agents or to study the multistage development of colon cancer.

Nevertheless, as every animal model, the DMH/AOM rat model also has limitations, which need to be taken into account before conducting animal research. This includes DMH/AOM metabolic activation and the metastatic potential of colonic adenocarcinomas. As has already been mentioned, DMH/AOM are indirect carcinogens, which need metabolic activation to become the active carcinogen methyldiazonium ion. This process occurs in the liver with the participation of various enzymes [15, 111]. If the putative chemopreventive agent interferes with the metabolic pathway of DMH/AOM, it may modify colon carcinogenesis and affect the results. It has already been demonstrated that disulfiram significantly affects colon carcinogenesis, because it blocks the metabolism of AOM due to its inhibitory activity on CYP2E1. CYP2E1 has been unambiguously shown to be an important enzyme involved in DMH/AOM metabolism [111]. It has also been found that simultaneous administration of DMH/AOM and alcohol inhibits colon carcinogenesis, probably due to suppression of DMH/AOM activation in the liver $[112,113]$. DMH/AOMinduced colon carcinogenesis may thus be either inhibited or enhanced by substances that are administered during the initiation stage. To avoid interference between the compound and $\mathrm{DMH} / \mathrm{AOM}$ activation, chemopreventive treatment can begin after carcinogen administration, that is, during the promotion or progression phase [5]. However, when a new pharmacological compound is tested for its effect, it is usually 
given in all the phases of colon carcinogenesis $[5,61]$. If the agent modifies colon carcinogenesis at the initiation stage, it is important to determine whether carcinogen metabolism is being influenced and, if so, to identify the enzymes involved [111].

In humans, lymphatic and hematogenous metastases are common if colon tumours are not identified and removed at an early stage. In contrast with humans, metastases to the liver and lung are very uncommon in the DMH/AOM rat model. Tumours that are capable of metastasis are almost exclusively mucinous and signet ring cells carcinomas of the proximal colon. Adenocarcinomas of the distal colon have not been shown to metastasise. Metastases are generally found in regional lymph nodes or on the peritoneal surface [8].

\section{Conclusion}

The evidence from various studies summarized in this paper demonstrate that the DMH/AOM rat model possesses many characteristics found in human sporadic CC, which makes it an important tool for studying different aspects of CC that cannot be effectively studied in humans. Studies on the DMH/AOM model allow monitoring the stepwise development of CC under defined experimental conditions. They have already produced much important information concerning the histology and biochemistry of tumour development, as well as about factors that retard or enhance tumorigenesis. Although the $\mathrm{DMH} / \mathrm{AOM}$ rat model does not represent the complexity of the human disease and does not replace studies with patient material, it is a valuable tool for studying the molecular events of CC and for developing and evaluating a variety of novel cancer chemopreventive agents or emerging therapeutic strategies that are difficult to address in humans.

Finally, it should be recognized that animal models often reflect only certain elements of pathophysiology and that the quality of the answer strongly depends on the quality and specificity of the experimental question asked.

\section{References}

[1] D. M. Parkin, F. Bray, J. Ferlay, and P. Pisani, "Global cancer statistics, 2002," CA Cancer Journal for Clinicians, vol. 55, no. 2, pp. 74-108, 2005.

[2] Y. S. Kim and J. A. Milner, "Dietary modulation of colon cancer risk," Journal of Nutrition, vol. 137, no. 11, pp. S2576S2579, 2007.

[3] A. E. Tammariello and J. A. Milner, "Mouse models for unraveling the importance of diet in colon cancer prevention," Journal of Nutritional Biochemistry, vol. 21, no. 2, pp. 77-88, 2010.

[4] D. E. Corpet and F. Pierre, "How good are rodent models of carcinogenesis in predicting efficacy in humans? A systematic review and meta-analysis of colon chemoprevention in rats, mice and men," European Journal of Cancer, vol. 41, no. 13, pp. 1911-1922, 2005.

[5] M. J. Wargovich, A. Jimenez, K. McKee et al., "Efficacy of potential chemopreventive agents on rat colon aberrant crypt formation and progression," Carcinogenesis, vol. 21, no. 6, pp. 1149-1155, 2000.

[6] J. Heyer, K. Yang, M. Lipkin, W. Edelmann, and R. Kucherlapati, "Mouse models for colorectal cancer," Oncogene, vol. 18 , no. 38, pp. 5325-5333, 1999.

[7] A. M. Femia and G. Caderni, "Rodent models of colon carcinogenesis for the study of chemopreventive activity of natural products," Planta Medica, vol. 74, no. 13, pp. 1602$1607,2008$.

[8] M. Perše and A. Cerar, "The dimethylhydrazine induced colorectal tumours in rat-experimental colorectal carcinogenesis," Radiology and Oncology, vol. 39, no. 1, pp. 61-87, 2005.

[9] R. P. Bird, "Aberrant crypt foci system to study cancer preventive agents in the colon," in Methods in Molecular Medicine: Tumor Marker Protocols, M. Hanausek and Z. Walaszek, Eds., pp. 465-474, Humana Press, Totowa, NJ, USA, 1998.

[10] H. Nakagama, M. Ochiai, T. Ubagai et al., "A rat colon cancer model induced by 2-amino-1-methyl-6-phenylimidazo[4,5b]pyridine, PhIP," Mutation Research, vol. 506-507, pp. 137$144,2002$.

[11] A. Banerjee and P. Quirke, "Experimental models of colorectal cancer," Diseases of the Colon and Rectum, vol. 41, no. 4, pp. 490-505, 1998.

[12] D. W. Rosenberg, C. Giardina, and T. Tanaka, "Mouse models for the study of colon carcinogenesis," Carcinogenesis, vol. 30, no. 2, pp. 183-196, 2009.

[13] J. Chen and XU. F. Huang, "The signal pathways in azoxymethane-induced colon cancer and preventive implications," Cancer Biology \& Therapy, vol. 8, no. 14, pp. 13131317, 2009.

[14] M. Takahashi and K. Wakabayashi, "Gene mutations and altered gene expression in azoxymethane-induced colon carcinogenesis in rodents," Cancer Science, vol. 95, no. 6, pp. 475-480, 2004.

[15] E. S. Fiala and C. Stathopoulos, "Metabolism of methylazoxymethanol acetate in the F344 rat and strain-2 guinea pig and its inhibition by pyrazole and disulfiram," Journal of Cancer Research and Clinical Oncology, vol. 108, no. 1, pp. 129-134, 1984.

[16] H. P. Glauert and M. R. Bennink, "Metabolism of 1,2dimethylhydrazine by cultured rat colon epithelial cells," Nutrition and Cancer, vol. 5, no. 2, pp. 78-86, 1983.

[17] C. T. Oravec, C. A. Jones, and E. Huberman, "Activation of the colon carcinogen 1,2-dimethylhydrazine in a rat colon cell-mediated mutagenesis assay," Cancer Research, vol. 46, no. 10 , pp. 5068-5071, 1986.

[18] W. W. L. Chang, "Histogenesis of colon cancer in experimental animals," Scandinavian Journal of Gastroenterology, vol. 19, supplement, pp. 27-43, 1984.

[19] T. Shirai, J. Nakanowatari, and Y. Kurata, "Different doseresponse relationships in the induction of different types of colonic tumors in wistar rats by 1,2-dimethylhydrazine," Gann, The Japanese Journal of Cancer Research, vol. 74, no. 1, pp. 21-27, 1983.

[20] Z. Večerić and A. Cerar, "Comparison of Wistar vs. Fischer rat in the incidence of 1,2-dimethylhydrazine induced intestinal tumors," Radiology and Oncology, vol. 38, no. 3, pp. 227247, 2004.

[21] L. Breskvar and A. Cerar, "A role of gender in the occurrence of dimethylhydrazine induced colorectal tumors in Wistar rats," Radiology and Oncology, vol. 31, no. 4, pp. 374-379, 1997. 
[22] T. F. McMahon, J. O. Peggins, M. M. Centra, and M. Weiner, "Age-related changes in biotransformation of azoxymethane and methylazoxymethanol in vitro," Xenobiotica, vol. 20, no. 5, pp. 501-513, 1990.

[23] B. A. Magnuson, E. H. South, J. H. Exon et al., "Increased susceptibility of adult rats to azoxymethane-induced aberrant crypt foci," Cancer Letters, vol. 161, no. 2, pp. 185-193, 2000.

[24] R. P. Bird and C. K. Good, "The significance of aberrant crypt foci in understanding the pathogenesis of colon cancer," Toxicology Letters, vol. 112-113, pp. 395-402, 2000.

[25] R. P. Bird, "Role of aberrant crypt foci in understanding the pathogenesis of colon cancer," Cancer Letters, vol. 93, no. 1, pp. 55-71, 1995.

[26] T. Tanaka, "Colorectal carcinogenesis: review of human and experimental animal studies," Journal of Carcinogenesis, vol. 8, article 5, 2009.

[27] H. Mori, Y. Yamada, T. Kuno, and Y. Hirose, "Aberrant crypt foci and $\beta$-catenin accumulated crypts; significance and roles for colorectal carcinogenesis," Mutation Research, vol. 566, no. 3, pp. 191-208, 2004.

[28] H. Mori, K. Hata, Y. Yamada, T. Kuno, and A. Hara, "Significance and role of early-lesions in experimental colorectal carcinogenesis," Chemico-Biological Interactions, vol. 155, no. 1-2, pp. 1-9, 2005.

[29] G. P. Boivin, K. Washington, K. Yang et al., "Pathology of mouse models of intestinal cancer: consensus report and recommendations," Gastroenterology, vol. 124, no. 3, pp. 762-777, 2003.

[30] G. Caderni, A. P. Femia, A. Giannini et al., "Identification of mucin-depleted foci in the unsectioned colon of azoxymethane-treated rats: correlation with carcinogenesis," Cancer Research, vol. 63, no. 10, pp. 2388-2392, 2003.

[31] R. P. Bird, "Observation and quantification of aberrant crypts in the murine colon treated with a colon carcinogen: preliminary findings," Cancer Letters, vol. 37, no. 2, pp. 147$151,1987$.

[32] Q. Lu, BO. Jiang, C. Lin, and T. Shan, "Dark Aberrant Crypt Foci with activated Wnt pathway are related to tumorigenesis in the colon of AOM-treated rat," Journal of Experimental and Clinical Cancer Research, vol. 27, no. 1, article 26, 2008.

[33] J. E. Paulsen, E. M. Løberg, H. B. Ølstørn, H. Knutsen, I. L. Steffensen, and J. Alexander, "Flat dysplastic aberrant crypt foci are related to tumorigenesis in the colon of azoxymethane-treated rat," Cancer Research, vol. 65, no. 1, pp. 121-129, 2005.

[34] M. Ochiai, M. Watanabe, M. Nakanishi, A. Taguchi, T. Sugimura, and H. Nakagama, "Differential staining of dysplastic aberrant crypt foci in the colon facilitates prediction of carcinogenic potentials of chemicals in rats," Cancer Letters, vol. 220, no. 1, pp. 67-74, 2005.

[35] Y. Yamada, N. Yoshimi, Y. Hirose et al., "Frequent $\beta$-catenin gene mutations and accumulations of the protein in the putative preneoplastic lesions lacking macroscopic aberrant crypt foci appearance, in rat colon carcinogenesis," Cancer Research, vol. 60, no. 13, pp. 3323-3327, 2000.

[36] T. P. Pretlow, B. J. Barrow, W. S. Ashton et al., "Aberrant crypts: putative preneoplastic foci in human colonic mucosa," Cancer Research, vol. 51, no. 5, pp. 1564-1567, 1991.

[37] T. P. Pretlow and T. G. Pretlow, "Mutant KRAS in aberrant crypt foci (ACF): initiation of colorectal cancer?" Biochimica et Biophysica Acta, vol. 1756, no. 2, pp. 83-96, 2005.
[38] L. Cheng and M. D. Lai, "Aberrant crypt foci as microscopic precursors of colorectal cancer," World Journal of Gastroenterology, vol. 9, no. 12, pp. 2642-2649, 2003.

[39] T. P. Pretlow, M. A. O'Riordan, K. M. Spancake, and T. G. Pretlow, "Two types of putative preneoplastic lesions identified by hexosaminidase activity in whole-mounts of colons from F344 rats treated with carcinogen," American Journal of Pathology, vol. 142, no. 6, pp. 1695-1700, 1993.

[40] K. Otori, K. Sugiyama, T. Hasebe, S. Fukushima, and H. Esumi, "Emergence of adenomatous aberrant crypt foci (ACF) from hyperplastic ACF with concomitant increase in cell proliferation," Cancer Research, vol. 55, no. 21, pp. 47434746, 1995.

[41] E. A. McLellan, A. Medline, and R. P. Bird, "Sequential analyses of the growth and morphological characteristics of aberrant crypt foci: putative preneoplastic lesions," Cancer Research, vol. 51, no. 19, pp. 5270-5274, 1991.

[42] J. Raju, "Azoxymethane-induced rat aberrant crypt foci: relevance in studying chemoprevention of colon cancer," World Journal of Gastroenterology, vol. 14, no. 43, pp. 66326635, 2008

[43] H. S. Park, R. A. Goodlad, and N. A. Wright, "The incidence of aberrant crypt foci and colonic carcinoma in dimethylhydrazine-treated rats varies in a site-specific manner and depends on tumor histology," Cancer Research, vol. 57, no. 20, pp. 4507-4510, 1997.

[44] M. A. M. Rodrigues, L. A. G. Silva, D. M. F. Salvadori, J. L. V. De Camargo, and M. R. Montenegro, "Aberrant crypt foci and colon cancer: comparison between a short-and mediumterm bioassay for colon carcinogenesis using dimethylhydrazine in Wistar rats," Brazilian Journal of Medical and Biological Research, vol. 35, no. 3, pp. 351-355, 2002.

[45] M. Ghirardi, R. Nascimbeni, V. Villanacci, M. G. Fontana, E. Di Betta, and B. Salerni, "Azoxymethane-induced aberrant crypt foci and colorectal tumors in F344 rats: sequential analysis of growth," European Surgical Research, vol. 31, no. 3, pp. 272-280, 1999.

[46] A. P. Femia, B. Bendinelli, A. Giannini et al., "Mucin-depleted foci have $\beta$-catenin gene mutations, altered expression of its protein, and are dose-and time-dependent in the colon of 1,2-dimethylhydrazine-treated rats," International Journal of Cancer, vol. 116, no. 1, pp. 9-15, 2005.

[47] A. P. Femia, E. Tarquini, M. Salvadori et al., "K-ras mutations and mucin profile in preneoplastic lesions and colon tumors induced in rats by 1,2-dimethylhydrazine," International Journal of Cancer, vol. 122, no. 1, pp. 117-123, 2008.

[48] A. P. Femia, P. Dolara, A. Giannini, M. Salvadori, A. Biggeri, and G. Caderni, "Frequent mutation of Apc gene in rat colon tumors and mucin-depleted foci, preneoplastic lesions in experimental colon carcinogenesis," Cancer Research, vol. 67, no. 2, pp. 445-449, 2007.

[49] A. P. Femia, P. Dolara, C. Luceri, M. Salvadori, and G. Caderni, "Mucin-depleted foci show strong activation of inflammatory markers in 1,2-dimethylhydrazine-induced carcinogenesis and are promoted by the inflammatory agent sodium dextran sulfate," International Journal of Cancer, vol. 125, no. 3, pp. 541-547, 2009.

[50] A. Pietro Femia, P. Dolara, and G. Caderni, "Mucin-depleted foci (MDF) in the colon of rats treated with azoxymethane (AOM) are useful biomakers for colon carcinogenesis," Carcinogenesis, vol. 25, no. 2, pp. 277-281, 2004.

[51] Y. Yamada, N. Yoshimi, Y. Hirose et al., "Sequential analysis of morphological and biological properties of $\beta$ catenin-accumulated crypts, provable premalignant lesions 
independent of aberrant crypt foci in rat colon carcinogenesis," Cancer Research, vol. 61, no. 5, pp. 1874-1878, 2001.

[52] N. Yoshimi, T. Morioka, T. Kinjo et al., "Histological and immunohistochemical observations of mucin-depleted foci (MDF) stained with Alcian blue, in rat colon carcinogenesis induced with 1,2-dimethylhydrazine dihydrochloride," Cancer Science, vol. 95, no. 10, pp. 792-797, 2004.

[53] A. P. Femia, J. E. Paulsen, P. Dolara, J. Alexander, and G. Caderni, "Correspondence between flat aberrant crypt foci and mucin-depleted foci in rodent colon carcinogenesis," Anticancer Research, vol. 28, no. 6 A, pp. 3771-3775, 2008.

[54] A. B. Sparks, P. J. Morin, B. Vogelstein, and K. W. Kinzler, "Mutational analysis of the APC/ $\beta$-catenin/Tcf pathway in colorectal cancer," Cancer Research, vol. 58, no. 6, pp. 11301134, 1998.

[55] R. P. Bird, D. Salo, C. Lasko, and C. Good, "A novel methodological approach to study the level of specific protein and gene expression in aberrant crypt foci putative preneoplastic colonic lesions by Western blotting and RTPCR," Cancer Letters, vol. 116, no. 1, pp. 15-19, 1997.

[56] C. Liu and J. Crawford, "The gastrointestinal tract," in Robbins and Cotran Patologic Basis of Disease, V. Kumar, A. Abbas, and N. Fausto, Eds., pp. 797-875, Elsevier Saunders, 2004.

[57] P. J. Morin, A. B. Sparks, V. Korinek et al., "Activation of $\beta$-catenin-Tcf signaling in colon cancer by mutations in $\beta$ catenin or APC," Science, vol. 275, no. 5307, pp. 1787-1790, 1997.

[58] C. De Filippo, G. Caderni, M. Bazzicalupo et al., "Mutations of the Apc gene in experimental colorectal carcinogenesis induced by azoxymethane in F344 rats," British Journal of Cancer, vol. 77, no. 12, pp. 2148-2151, 1998.

[59] K. J. Sohn, M. Puchyr, R. N. Salomon et al., "The effect of dietary folate on Apc and p53 mutations in the dimethylhydrazine rat model of colorectal cancer," Carcinogenesis, vol. 20, no. 12, pp. 2345-2350, 1999.

[60] C. A. Blum, T. Tanaka, X. Zhong et al., "Mutational analysis of Ctnnb1 and Apc in tumors from rats given 1,2-dimethylhydrazine or 2-amino-3-methylimidazo[4,5f] quinoline: mutational 'hotspots' and the relative expression of $\beta$-catenin and c-jun," Molecular Carcinogenesis, vol. 36, no. 4, pp. 195-203, 2003.

[61] A. P. Femia, C. Luceri, S. Toti, A. Giannini, P. Dolara, and G. Caderni, "Gene expression profile and genomic alterations in colonic tumours induced by 1,2-dimethylhydrazine (DMH) in rats," BMC Cancer, vol. 10, article 194, 2010.

[62] M. Takahashi, M. Mutoh, T. Kawamori, T. Sugimura, and K. Wakabayashi, "Altered expression of $\beta$-catenin, inducible nitric oxide synthase and cyclooxygenase- 2 in azoxymethaneinduced rat colon carcinogenesis," Carcinogenesis, vol. 21, no. 7, pp. 1319-1327, 2000.

[63] M. Takahashi, K. Fukuda, T. Sugimura, and K. Wakabayashi, " $\beta$-catenin is frequently mutated and demonstrates altered cellular location in azoxymethane-induced rat colon tumors," Cancer Research, vol. 58, no. 1, pp. 42-46, 1998.

[64] M. Hajdúch, S. Jančík, J. Drábek, and D. Radzioch, "Clinical relevance of KRAS in human cancers," Journal of Biomedicine and Biotechnology, vol. 2010, Article ID 150960, 2010.

[65] A. A. Vivona, B. Shpitz, A. Medline et al., "K-ras mutations in aberrant crypt foci, adenomas and adenocarcinomas during azoxymethane-induced colon carcinogenesis," Carcinogenesis, vol. 14, no. 9, pp. 1777-1781, 1993.

[66] S. H. Erdman, H. D. Wu, L. J. Hixson, D. J. Ahnen, and E. W. Gerner, "Assessment of mutations in Ki-ras and p53 in colon cancers from azoxymethane- and dimethylhydrazine-treated rats," Molecular Carcinogenesis, vol. 19, no. 2, pp. 137-144, 1997.

[67] C. Luceri, C. De Filippo, G. Caderni et al., "Detection of somatic DNA alterations in azoxymethane-induced F344 rat colon tumors by random amplified polymorphic DNA analysis," Carcinogenesis, vol. 21, no. 9, pp. 1753-1756, 2000.

[68] M. Bissonnette, S. Khare, F. C. Von Lintig et al., "Mutational and nonmutational activation of $\mathrm{p} 21$ in rat colonic azoxymethane-induced tumors: effects on mitogen-activated protein kinase, cyclooxygenase-2, and cyclin D1," Cancer Research, vol. 60, no. 16, pp. 4602-4609, 2000.

[69] R. F. Jacoby, X. Llor, B. B. Teng, N. O. Davidson, and T. A. Brasitus, "Mutations in the K-ras oncogene induced by 1,2-dimethylhydrazine in preneoplastic and neoplastic rat colonic mucosa," Journal of Clinical Investigation, vol. 87, no. 2, pp. 624-630, 1991.

[70] S. A. Stopera, L. C. Murphy, and R. P. Bird, "Evidence for a ras gene mutation in azoxymethane-induced colonic aberrant crypts in Sprague-Dawley rats: earliest recognizable precursor lesions of experimental colon cancer," Carcinogenesis, vol. 13, no. 11, pp. 2081-2085, 1992.

[71] M. Perse, V. Mlinaric, and A. Cerar, "Aberrant crypt foci as biomarkers predictive of colorectal carcinoma," Slovenian Medical Journal, vol. 79, no. 6, pp. 499-506, 2010.

[72] N. Shivapurkar, K. J. Nikula, T. Tanaka, Z. C. Tang, and O. Alabaster, "Absence of p53 gene mutations in rat colon carcinomas induced through the synergistic interaction between methylazoxymethanol and X-irradiation," Cancer Letters, vol. 113, no. 1-2, pp. 9-16, 1997.

[73] N. Shivapurkar, S. A. Belinsky, D. C. Wolf, Z. Tang, and O. Alabaster, "Absence of p53 gene mutations in rat colon carcinomas induced by azoxymethane," Cancer Letters, vol. 96, no. 1, pp. 63-70, 1995.

[74] S. A. Stopera and R. P. Bird, "Immunohistochemical demonstration of mutant p53 tumour suppressor gene product in aberrant crypt foci," Cytobios, vol. 73, no. 293, pp. 73-88, 1993.

[75] F. A. Orlando, D. Tan, J. D. Baltodano et al., "Aberrant crypt foci as precursors in colorectal cancer progression," Journal of Surgical Oncology, vol. 98, no. 3, pp. 207-213, 2008.

[76] M. Ravnik-Glavac, A. Cerar, and D. Glavac, "Animal model in the study of colorectal carcinogenesis," Pflugers Archiv European Journal of Physiology, vol. 440, no. 5, pp. R55-R57, 2000.

[77] M. Takahashi, S. Nakatsugi, T. Sugimura, and K. Wakabayashi, "Frequent mutations of the $\beta$-catenin gene in mouse colon tumors induced by azoxymethane," Carcinogenesis, vol. 21, no. 6, pp. 1117-1120, 2000.

[78] T. A. De Jong, S. A. Skinner, C. Malcontenti-Wilson et al., "Inhibition of rat colon tumors by sulindac and sulindac sulfone is independent of K-ras (codon 12) mutation," American Journal of Physiology - Gastrointestinal and Liver Physiology, vol. 278, no. 2, pp. G266-G272, 2000.

[79] Y. Kishimoto, T. Morisawa, A. Hosoda, G. Shiota, H. Kawasaki, and J. Hasegawa, "Molecular changes in the early stage of colon carcinogenesis in rats treated with azoxymethane," Journal of Experimental and Clinical Cancer Research, vol. 21, no. 2, pp. 203-211, 2002.

[80] M. Bordonaro, "Modular Cre/lox system and genetic therapeutics for colorectal cancer," Journal of Biomedicine and Biotechnology, vol. 2009, Article ID 358230, 2009.

[81] T. Jin, I. George Fantus, and J. Sun, "Wnt and beyond Wnt: multiple mechanisms control the transcriptional property of 
$\beta$-catenin," Cellular Signalling, vol. 20, no. 10, pp. 1697-1704, 2008.

[82] F. T. Kolligs, G. Bommer, and B. Göke, "Wnt/betacatenin/Tcf signaling: a critical pathway in gastrointestinal tumorigenesis," Digestion, vol. 66, no. 3, pp. 131-144, 2002.

[83] . Xing Pei Hao, T. G. Pretlow, J. S. Rao, and T. P. Pretlow, “ $\beta$ catenin expression is altered in human colonic aberrant crypt foci," Cancer Research, vol. 61, no. 22, pp. 8085-8088, 2001.

[84] R. K. Wali, S. Khare, M. Tretiakova et al., "Ursodeoxycholic acid and F-D inhibit aberrant crypt proliferation in the rat azoxymethane model of colon cancer: roles of cyclin D1 and E-cadherin," Cancer Epidemiology Biomarkers and Prevention, vol. 11, no. 12, pp. 1653-1662, 2002.

[85] K. Otori, K. Sugiyama, S. Fukushima, and H. Esumi, "Expression of the cyclin D1 gene in rat colorectal aberrant crypt foci and tumors induced by azoxymethane," Cancer Letters, vol. 140, no. 1-2, pp. 99-104, 1999.

[86] Y. Kishimoto, K. Yashima, T. Morisawa, G. Shiota, H. Kawasaki, and J. Hasegawa, "Effects of cyclooxygenase-2 inhibitor NS-398 on APC and c-myc expression in rat colon carcinogenesis induced by azoxymethane," Journal of Gastroenterology, vol. 37, no. 3, pp. 186-193, 2002.

[87] O. Takayama, H. Yamamoto, B. Damdinsuren et al., "Expression of PPAR $\delta$ in multistage carcinogenesis of the colorectum: implications of malignant cancer morphology," British Journal of Cancer, vol. 95, no. 7, pp. 889-895, 2006.

[88] H. K. Roy, W. J. Karolski, and A. Ratashak, "Distal bowel selectivity in the chemoprevention of experimental colon carcinogenesis by the non-steroidal anti-inflammatory drug nabumetone," International Journal of Cancer, vol. 92, no. 4, pp. 609-615, 2001.

[89] H. K. Roy, B. F. Olusola, D. L. Clemens et al., "AKT protooncogene overexpression is an early event during sporadic colon carcinogenesis," Carcinogenesis, vol. 23, no. 1, pp. 201205, 2002.

[90] I. Thorup, "Histomorphological and immunohistochemical characterization of colonic aberrant crypt foci in rats: relationship to growth factor expression," Carcinogenesis, vol. 18, no. 3, pp. 465-472, 1997.

[91] J. Shao, H. Sheng, R. Aramandla et al., "Coordinate regulation of cyclooxygenase- 2 and TGF- $\beta 1$ in replication errorpositive colon cancer and azoxymethane-induced rat colonic tumors," Carcinogenesis, vol. 20, no. 2, pp. 185-191, 1999.

[92] J. Massagué, “TGF $\beta$ in Cancer," Cell, vol. 134, no. 2, pp. 215230, 2008.

[93] E. Spisni, A. Strillacci, C. Griffoni, M. C. Valerii, G. Lazzarini, and V. Tomasi, "RNAi-based strategies for cyclooxygenase-2 inhibition in cancer," Journal of Biomedicine and Biotechnology, vol. 2010, Article ID 828045, 2010.

[94] R. N. DuBois, A. Radhika, B. S. Reddy, and A. J. Entingh, "Increased cyclooxygenase-2 levels in carcinogen-induced rat colonic tumors," Gastroenterology, vol. 110, no. 4, pp. 12591262, 1996.

[95] M. Perše, A. Zebic, and A. Cerar, "Rofecoxib does not inhibit aberrant crypt foci formation but inhibits later steps in the development of experimental colorectal cancer: rofecoxib in experimental colon cancer," Scandinavian Journal of Gastroenterology, vol. 40, no. 1, pp. 61-67, 2005.

[96] T. Kawamori, M. Takahashi, K. Watanabe et al., "Suppression of azoxymethane-induced colonic aberrant crypt foci by a nitric oxide synthase inhibitor," Cancer Letters, vol. 148, no. 1, pp. 33-37, 2000.

[97] K. E. Kearney, T. G. Pretlow, and T. P. Pretlow, "Increased expression of fatty acid synthase in human aberrant crypt foci: possible target for colorectal cancer prevention," International Journal of Cancer, vol. 125, no. 1, pp. 249-252, 2009.

[98] D. S. Y. Lau and M. C. Archer, "Fatty acid synthase is overexpressed in large aberrant crypt foci in rats treated with azoxymethane," International Journal of Cancer, vol. 124, no. 11, pp. 2750-2753, 2009.

[99] R. Marzocchini, F. Malentacchi, M. Biagini et al., "The expression of low molecular weight protein tyrosine phosphatase is up-regulated in 1,2-dimethylhydrazine-induced colon tumours in rats," International Journal of Cancer, vol. 122, no. 7, pp. 1675-1678, 2008.

[100] T. Devasena, V. P. Menon, and K. N. Rajasekharan, "Prevention of 1,2-dimethylhydrazine-induced circulatory oxidative stress by bis-1,7-(2-hydroxyphenyl)-hepta-1,6-diene3,5-dione during colon carcinogenesis," Pharmacological Reports, vol. 58, no. 2, pp. 229-235, 2006.

[101] M. Perše, R. Injac, B. Štrukelj, and A. Cerar, "Effects of highfat mixed-lipid diet and exercise on the antioxidant system in skeletal and cardiac muscles of rats with colon carcinoma," Pharmacological Reports, vol. 61, no. 5, pp. 909-916, 2009.

[102] R. Injac, M. Perse, M. Cerne et al., "Protective effects of fullerenol $\mathrm{C}(\mathrm{OH})$ against doxorubicin-induced cardiotoxicity and hepatotoxicity in rats with colorectal cancer," Biomaterials, vol. 30, no. 6, pp. 1184-1196, 2009.

[103] V. Sreedharan, K. K. Venkatachalam, and N. Namasivayam, "Effect of morin on tissue lipid peroxidation and antioxidant status in 1,2-dimethylhydrazine induced experimental colon carcinogenesis," Investigational New Drugs, vol. 27, no. 1, pp. 21-30, 2009.

[104] J. S. Giftson, S. Jayanthi, and N. Nalini, "Chemopreventive efficacy of gallic acid, an antioxidant and anticarcinogenic polyphenol, against 1,2-dimethyl hydrazine induced rat colon carcinogenesis," Investigational New Drugs, vol. 28, no. 3, pp. 251-259, 2010.

[105] V. Manju, V. Balasubramaniyan, and N. Nalini, "Rat colonic lipid peroxidation and antioxidant status: the effects of dietary luteolin on 1,2-dimethylhydrazine challenge," Cellular and Molecular Biology Letters, vol. 10, no. 3, pp. 535-551, 2005.

[106] S. Samanta, V. Swamy, D. Suresh et al., "Protective effects of vanadium against DMH-induced genotoxicity and carcinogenesis in rat colon: removal of O-methylguanine DNA adducts, p53 expression, inducible nitric oxide synthase downregulation and apoptotic induction," Mutation Research, vol. 650, no. 2, pp. 123-131, 2008.

[107] J. P. Sunter, D. R. Appleton, N. A. Wright, and A. J. Watson, "Pathological features of the colonic tumours induced in rats by the administration of 1,2-dimethylhydrazine," Virchows Archiv B Cell Pathology, vol. 29, no. 1, pp. 211-223, 1978.

[108] T. J. McGarrity, L. P. Peiffer, and P. C. Colony, "Cellular proliferation in proximal and distal rat colon during 1,2dimethylhydrazine-induced carcinogenesis," Gastroenterology, vol. 95, no. 2, pp. 343-348, 1988.

[109] M. Gamberini, M. R. Cidade, L. A. Valotta, M. C. S. Armelin, and L. C. C. Leite, "Contribution of hydrazinesderived alkyl radicals to cytotoxicity and transformation induced in normal c-myc-overexpressing mouse fibroblasts," Carcinogenesis, vol. 19, no. 1, pp. 147-155, 1998.

[110] J. Hau, "Animal models," in Handbook of Laboratory Animal Sience: Animal Models, J. Hau and G. van Hoosier, Eds., pp. 1-9, CRC Press, Boca Raton, Fla, USA, 2003.

[111] O. S. Sohn, E. S. Fiala, S. P. Requeijo, J. H. Weisburger, and F. J. Gonzalez, "Differential effects of CYP2E1 status on the metabolic activation of the colon carcinogens azoxymethane 
and methylazoxymethanol," Cancer Research, vol. 61, no. 23, pp. 8435-8440, 2001.

[112] M. Perše and A. Cerar, "Dimethylhydrazine model is not appropriate for evaluating effect of ethanol on colorectal cancer," Revista Espanola de Enfermedades Digestivas, vol. 99, no. 8, pp. 463-466, 2007.

[113] J. F. Noguera Aguilar and A. Cuadrado García, "Ethanol and colic experimental carcinogenesisEtanol y carcinogénesis cólica experimental," Revista Espanola de Enfermedades Digestivas, vol. 99, no. 8, pp. 438-439, 2007. 


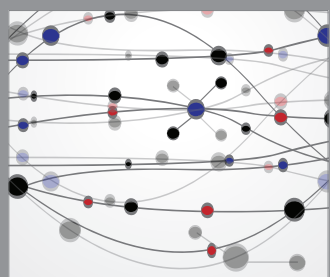

The Scientific World Journal
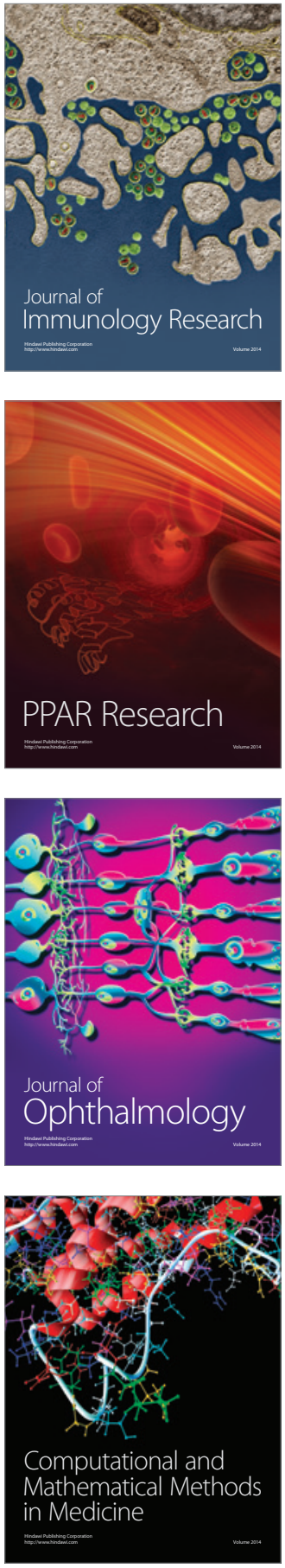

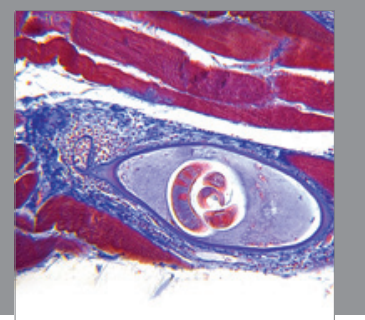

Gastroenterology

Research and Practice
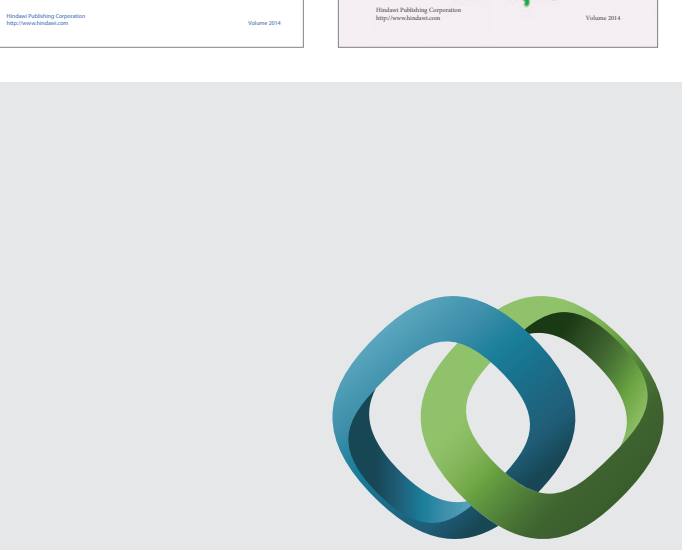

\section{Hindawi}

Submit your manuscripts at

http://www.hindawi.com
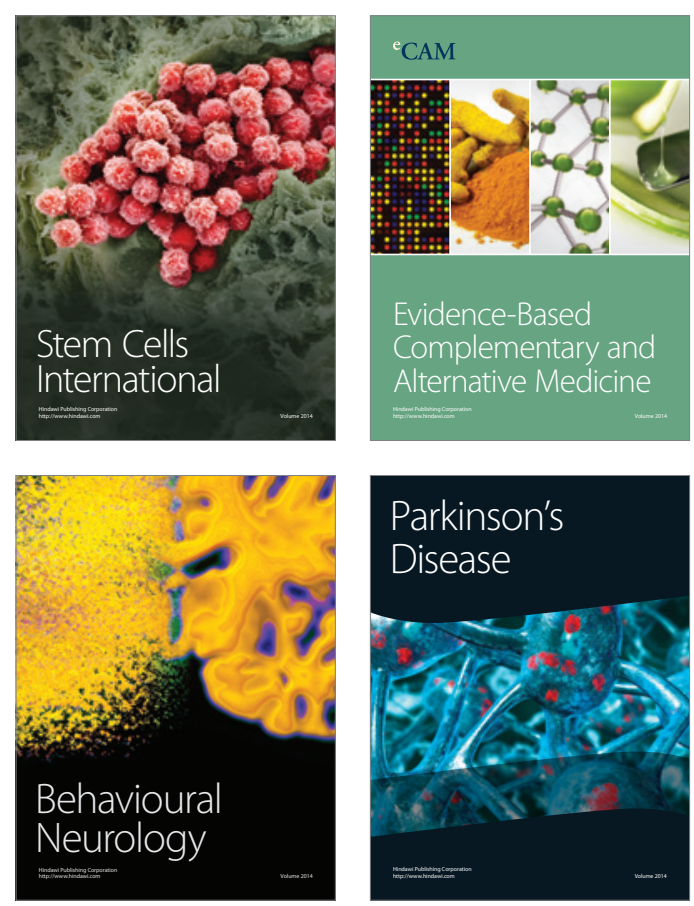

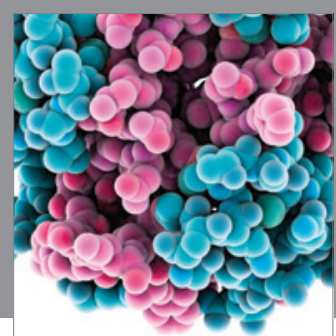

Journal of
Diabetes Research

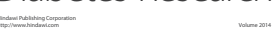

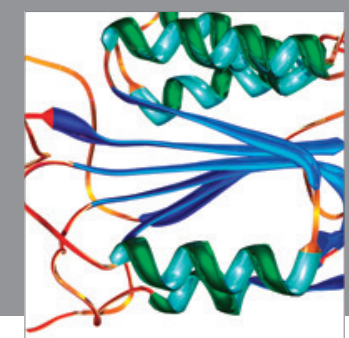

Disease Markers
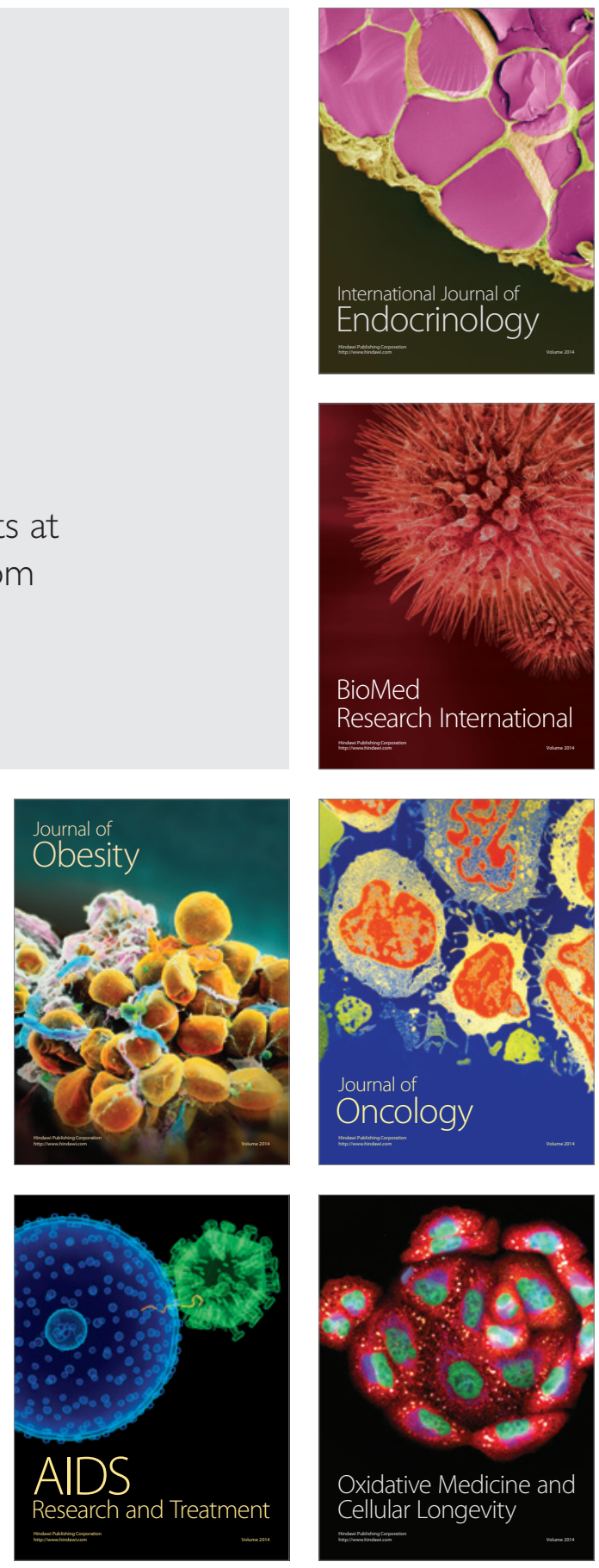